\title{
LOOP DIURETICS IN HEART FAILURE: EVIDENCE-BASED CHOICE
}

DOI: 10.36740/WLek202104136

\author{
Maryana M. Rosul, Miroslava M. Bletskan, Nataliya V. Ivano, Marina 0. Korabelschykova \\ STATE HIGHER EDUCATIONAL ESTABLISHMENT “UZHHOROD NATIONAL UNIVERSITY”, UZHHOROD, UKRAINE
}

\begin{abstract}
The aim: Of the article is to conduct a comparative evaluation of the effectiveness of torasemide and furosemide in patients with heart failure.

Materials and methods: Analysis of the existing clinical trials and meta-analyzes that combine the results of the completed studies aimed at the investigation of comparative efficacy of furosemide and torasemide in patients with heart failure (HF).

Conclusions: There is enough convincing evidence to speak about the advantages of torasemide over furosemide both in terms of its pharmacological properties and taking into account the reduction of hospitalizations, functional progress and improvement in the quality of life of patients with HF. The safety profile of torasemide is more favorable, as it is associated with a reduced risk of hypokalemia compared to furosemide. The abovementioned facts favor the use of torasemide in patients with symptomatic $\mathrm{HF}$, as well as the transition from furosemide to torasemide in patients with edema caused by $\mathrm{HF}$, which remain uncontrolled despite receiving optimal doses of furosemide.
\end{abstract}

KEY WORDS: heart failure, torasemide, furosemide

Wiad Lek. 2021;74(4):1003-1006

\section{INTRODUCTION}

Heart failure is one of the commonest diseases in the world. The main manifestations of HF are the symptoms associated with fluid retention and congestion, including shortness of breath, edema, and impaired perfusion of tissues and organs. In its turn, fluid retention, congestion and severe symptoms caused by them are associated with reduced performance and impaired quality of life, increased risk of hospitalization and adverse effects [1]. Therefore, use of diuretics, including loop diuretics, is an important component of complex therapy of patients with HF.

The current guidelines do not have a clear answer to the question of which of the modern loop diuretics has advantages when used in patients with HF. At the current stage, the question of choosing the best loop diuretic remains debatable $[2,3]$. Furosemide appeared on the pharmaceutical market earlier than torasemide. As a result, experience of furosemide usage in clinical settings is much greater than the experience of torasemide. However, the principles of evidence-based medicine require that, if there is a choice in treatment, the drug with the best effect on the patient's quality of life and prognosis must be used.

\section{THE AIM}

The aim is to conduct a comparative evaluation of the effectiveness of torasemide and furosemide in patients with HF.

\section{MATERIALS AND METHODS}

Analysis of the existing clinical trials and meta-analyzes that combine the results of the completed studies aimed at the investigation of the comparative efficacy of furosemide and torasemide in patients with HF.

\section{REVIEW AND DISCUSSION}

Loop diuretics remain the most effective means of reducing the clinical symptoms and signs of HF. To date, there are numerous studies that indicate the advantages of torasemide over furosemide in the treatment of patients with HF.

In an open-label TORIC study (Torasemide in Congestive Heart Failure), torasemide has shown clear beneficial effects on prognosis and a more significant improvement in the clinical condition of patients with HF compared with other diuretics, including furosemide. The study involved 1377 patients with chronic HF (NYHA II-III). Torasemide at a dose of $10 \mathrm{mg} /$ day compared with furosemide at a dose of $40 \mathrm{mg}$ / day and other diuretics significantly reduced overall mortality - by $51.5 \%$, cardiovascular death - by $59.7 \%$, sudden death - by $65.8 \%$. At the same time, functional improvement assessed as class reduction by New York Heart Association (NYHA) was observed in a larger number of patients receiving torasemide $(45.8 \%)$ than in patients receiving furosemide or other diuretics (37.2\%) ( $\mathrm{p}=0.00017)$. There was also better tolerability of the drug (torasemide) with less probability of side effects. It significantly less often led to the development of hypokalemia than furosemide (12.9 and $17.9 \%$, respectively, $\mathrm{p}=0.013)[4]$.

Another open-label randomized study of 237 patients with chronic HF (NYHA II-IV) (Müller K., 2003) has also shown a more significant clinical improvement by at least one NYHA class in patients treated with torasemide compared 
to furosemide ( $\mathrm{p}=0.014)$. In the given study, torasemide has shown significantly higher tolerability $(\mathrm{p}=0.0001)$ : reduced restrictions in daily life $(\mathrm{p}=0.0002)$, the number of mictions at 3, 6 and 12 hours after taking a diuretic $(\mathrm{p}<0,001$ at all time points) and urgency to urinate $(\mathrm{p}<0.0001)$ compared to treatment with furosemide [5].

In the study by Murray et al. (2001) involving 234 patients with chronic HF, there was a significant reduction in the frequency of rehospitalization for HF when comparing torasemide with furosemide ( $32 \%$ vs. $17 \%, \mathrm{p}<0.01)$ and other cardiovascular causes ( $59 \%$ vs. $44 \%, \mathrm{p}=0.03$ ). Patients in the torasemide group were hospitalized for HF almost for a twice less period (106 vs. 296 days in the furosemide group, $\mathrm{p}=0.02$ ) [6].

The results of several recently-conducted meta-analyzes studying comparative evaluation of the clinical effects from the mentioned loop diuretics in patients with HF have also shown the clinical advantages of torasemide over furosemide.

According to the analysis performed by DiNicolantonio (2012) there was a significant reduction in the overall risk of HF rehospitalization $(\mathrm{p}<0.0001)$, as well as a reduction in the risk of further HF rehospitalization $(\mathrm{p}=0.008)$ and cardiovascular events $(\mathrm{p}=0,03)$ in patients treated with torasemide and having at least one rehospitalization in the anamnesis. Moreover, the tendency for overall mortality reduction was also noticed in patients in the group of torasemide $(\mathrm{p}=0.54)$ [7].

The results of the meta-analysis by Shah et al. (2018) have shown that torasemide significantly reduced the risk of HF rehospitalization $(p<0.0001)$ and cardiovascular events $(p=0.01)$ compared with furosemide. The given results confirm the clinical advantage of the drug and indicate an increase in cost-effectiveness of HF therapy due to reduced costs of rehospitalization with torasemide: replacing furosemide with torasemide could save about $\$ 4$ billion per year through reducing the risk of rehospitalization for HF by $67 \%$. However, the analysis of the frequency of deaths and side effects has not revealed significant intergroup differences $(\mathrm{p}=0.38)[8]$.

The conducted meta-analysis by Kido et al. (2019) has shown that the use of torasemide in patients with decompensated HF was accompanied by a higher frequency of functional improvement by at least 1 NYHA class ( $45 \%$ vs. $36.1 \%, \mathrm{p}<0.0004)$. In the torasemide group there was a less pronounced decrease in blood potassium level compared with the use of furosemide and other diuretics used in HF. The proportion of patients with low potassium level was significantly higher in the group of furosemide and other diuretics than in the group of torasemide (17.9\% vs. $12.9 \%$; $\mathrm{p}=0.013$ ). There was no statistically significant difference in mortality rates between the torasemide and furosemide groups ( $\mathrm{p}=0.99$ ). Similarly, no statistically significant intergroup differences were found in the frequency of rehospitalizations for HF $(\mathrm{p}=0.15)$ and for cardiovascular events $(\mathrm{p}=0.22)[9]$.

A meta-analysis by Miles et al. (2019) has confirmed the advantage of torasemide in reducing the risk of rehospital- ization for $\mathrm{HF}$ and having functional improvement of NYHA class. However, overall mortality rates were similar between the torasemide and furosemide groups [10].

A meta-analysis by Abraham et al. has shown that the use of torasemide is associated with a much more pronounced functional improvement from NYHA III/IV to NYHA I/ II $(p=0.004)$, reduced mortality from cardiac causes compared with furosemide in patients with $\operatorname{HF}(p<0,001)$. The torasemide treatment results in a tendency to reduce the frequency of hospitalizations for HF compared with furosemide ( $p=0.07)$. The studied diuretics do not differ in the effect on overall mortality $(\mathrm{p}=0.65)$ and in the frequency of side effects in patients $(\mathrm{p}=0.48)$ [11].

Thus, all the results of the meta-analyzes of the main comparative studies of furosemide and torasemide in HF have shown that torasemide can significantly alleviate the course of HF and reduce the frequency of rehospitalizations for HF and cardiovascular events compared to furosemide. The safety profile of torasemide is also more favorable, as it is associated with a reduced risk of hypokalemia compared to furosemide. However, in terms of the effect of torasemide on the risk of death, the given meta-analyzes contradict the results of the already mentioned largest comparative study of torasemide TORIC (significant reduction in patient mortality along with vivid functional improvement of NYHA class). In this respect, it is especially long-awaited and relevant to obtain the results of the TRANSFORM-HF study launched in 2018, the main task of which is to determine whether there are differences between torasemide and furosemide in terms of impact on mortality from all the causes [12].

The favorable clinical effects of torasemide received in the course of the conducted research can be explained by important features of pharmacokinetics and mechanisms of action of the drug. The bioavailability of torasemide is a stable indicator, equals to $80-100 \%$ and does not depend on food intake or the presence of edema of the intestinal wall (common in HF). In its turn, the bioavailability of furosemide varies ranging between $10-90 \%$ and decreases in the case of taking the drug with food, as well as in patients with edema of the intestinal wall by approximately $30 \%$ [13]. In addition, torasemide is characterized by a faster onset (1.1 vs. $2.4 \mathrm{~h}$ ) and a longer duration (18-24 vs. $4-6 \mathrm{~h}$ ) of action compared to furosemide. Among other things, torasemide reduces the risk of postdiuretic rebound phenomenon in the form of water and sodium retention (due to lower likelihood of achieving subtherapeutic concentrations of the drug in blood compared with short-acting furosemide) [14]. Another advantage of the long-term effect of torasemide is the possibility to take the drug once a day (compared with the scheme 2 times a day, typical for furosemide). The smooth diuretic effect of torasemide is accompanied by a decrease in urination compared with furosemide and does not limit patients' activity, which in general increases adherence to treatment by approximately $13 \%$ [15].

Torasemide is proven to have an antialdosterone effect due to blockade of aldosterone receptors and decreased aldosterone synthesis $[13,16]$. Due to the antialdosterone effect, torasemide slows down the process of fibrosis in the 
myocardium and vascular wall, and also has a minimal kalliuretic effect, which reduces the risk of hypokalemia in contrast to furosemide. It is known that hypokalemia is associated with an increased risk of severe arrhythmias and worsening of the prognosis [11]. The use of drugs aimed at minimizing fibrosis can prevent heart dysfunction, reduce cardiac muscle stiffness, slow myocardial remodeling, reduce the risk of sudden death due to arrhythmias, improve cardiac function and reduce NYHA class, especially in patients with more pronounced myocardial fibrosis [17]. In the study by B. López et al. immediate-release (IR) torasemide has shown to reduce the bulk fraction of collagen and the development of fibrosis compared to furosemide. Myocardial fibrosis is the result of increased accumulation of type I collagen in the interstitium, as well as around the intramyocardial arteries and arterioles. Torasemide IR (according to endomyocardial biopsy) blocks the enzyme involved in the synthesis of molecules of this type of collagen [18]. Thus after 8 months of treatment it reduces the amount of collagen fraction in the myocardium in patients with chronic HF (NYHA II-IV) by 1.8 times. It is important to note that the diuretic activity and antifibrotic properties of torasemide are observed at different stages of treatment. Thus, antihypertensive and diuretic effects occur immediately after the initial dose, and the implementation of antifibrotic action can be observed after 6-9 months of continuous therapy [19].

At the same time, a large-scale TORAFIC study (the prolonged-release formulation of torasemide versus furosemide in patients with chronic heart failure) proves that the prolonged-release formulation of torasemide (torasemide-PR) has no effect on myocardial fibrosis. Inability of torasemide-PR to reduce myocardial fibrosis can probably be explained by the form of release and, consequently, the lower maximum concentration of the active substance in plasma, insufficient to trigger the mechanisms by which collagen synthesis is inhibited [20].

Considering the optimal choice of loop diuretic in patients with HF, we cannot disregard the new document of the European Society of Cardiology published in 2019 "The Use of Diuretics in Congestive Heart Failure - a Position Statement from the Heart Failure Association of the European Society of Cardiology.' This document draws doctors' attention for the first time to the advisability of patients' transition to torasemide after an acute episode of HF while previously taking furosemide: "For patients who developed an acute heart failure episode while previously taking a loop diuretic before admission, a higher dose following discharge might need to be used. Additionally, in case that this previous loop diuretic was furosemide, a switch to either bumetanide or torsemide might be considered, as they have a more predictable absorption pattern and bioavailability, especially in the face of subclinical congestion" [21].

\section{CONCLUSIONS}

To date, there have been enough convincing evidence to speak about the advantages of torasemide over furosemide both in terms of its pharmacological properties and the reduction in the frequency of hospitalizations, functional improvement, improving the quality of life of patients with heart failure. The safety profile of torasemide is also more favorable, as it is associated with a reduced risk of hypokalemia compared to furosemide. All these facts favor the use of torasemide in patients with symptomatic heart failure, as well as the transition from furosemide to torasemide in patients with edema caused by heart failure, which remains uncontrolled despite receiving optimal doses of furosemide.

\section{REFERENCES}

1. Gheorghiade M., Follath F., Ponikowski P. et al. Assessing and grading congestion in acute heart failure: a scientific statement from the Acute Heart Failure Committee of the Heart Failure Association of the European Society of Cardiology and endorsed by the European Society of Intensive Care Medicine. Eur J Heart Fail. 2010; 12(5): 423-433.

2. Ponikowski P., Voors A., Anker S. et al. 2016 ESC Guidelines for the diagnosis and treatment of acute and chronic heart failure: The Task Force for the diagnosis and treatment of acute and chronic heart failure of the European Society of Cardiology (ESC). Developed with the special contribution of the Heart Failure Association (HFA) of the ESC. Eur J Heart Fail. 2016; 18(8): 891-975.

3. Yancy C., Jessup M., Bozkurt B. et al. 2013 ACCF/AHA guideline for the management of heart failure: a report of the American College of Cardiology Foundation. American Heart Association Task Force on Practice Guidelines. J Am Coll Cardiol. 2013; 62(16): e147-239.

4. Cosín J., Díez J. TORIC investigators. Torasemide in chronic heart failure: results of the TORIC study. Eur J Heart Fail. 2002; 4(4): 507-513.

5. Müller K., Gamba G., Jaquet F., Hess B. Torasemide vs. furosemide in primary care patients with chronic heart failure NYHA II to IV - efficacy and quality of life. Eur J Heart Fail. 2003; 5(6):793-801.

6. Murray M.D., Deer M.M., Ferguson J.A. et al. Open-label randomized trial of torsemide compared with furosemide therapy for patients with heart failure. Am J Med. 2001; 111(7): 513-520.

7. DiNicolantonio J.J. Should torsemide be the loop diuretic of choice in systolic heart failure? Future Cardiol. 2012; 8 (5): 707-728.

8. Shah P., Patel H., Mithawala P., Doshi R. Torsemide versus furosemide in heart failure patients: A meta-analysis of randomized controlled trials. Eur J Intern Med. 2018; 57: e38-e40.

9. Kido K., Shimizu M., Hashiguchi M. Comparing torsemide versus furosemide in patients with heart failure: A meta-analysis. J Am Pharm Assoc. 2019; 59(3): 432-438.

10. Miles J., Hanumanthu B., Patel K. et al. Torsemide versus furosemide and intermediate-term outcomes in patients with heart failure: an updated meta-analysis. J Cardiovasc Med (Hagerstown). 2019; 20(6): 379-388.

11. Abraham B., Megaly M., Sous M. et al. Meta-Analysis Comparing Torsemide Versus Furosemide in Patients With Heart Failure. Am J Cardiol. 2020; 125(1): 92-99.

12. TRANSFORM-HF: ToRsemide compArisoN With furoSemide FOR Management of Heart Failure (TRANSFORM-HF). https://clinical-trials. gov/ct2/show/NCT03296813.

13. Buggey J., Mentz R., Pitt B. et al. A reappraisal of loop diuretic choice in heart failure patients. Am Heart J. 2015; 169 (3): 323-333.

14. Vargo D.L., KramerW.G., Black P.K. et al. Bioavailability, pharmacokinetics, and pharmacodynamics of torsemide and furosemide in patients with congestive heart failure. Clin Pharmacol Ther. 1995; 57(6): 601-609.

15. Claxton A., Cramer J., Pierce C. A systematic review of the associations between dose regimens and medication compliance. Clin Ther. 2001; 23(8): 1296-1310. 
16. Tsutamoto T., Sakai H., Wada A. et al. Torasemide inhibits transcardiac extraction of aldosterone in patients with congestive heart failure. J Am Coll Cardiol. 2004. 44(11): 2252-2253.

17. González A., Schelbert E., Díez J., Butler J. Myocardial Interstitial Fibrosis in Heart Failure: Biological and Translational Perspectives. J Am Coll Cardiol. 2018; 71(15): 1696-1706.

18. López B., González A., Beaumont J. et al. Identification of a potential cardiac antifibrotic mechanism of torasemide in patients with chronic heart failure. J Am Coll Cardiol. 2007; 50(9): 859-867.

19. López B., Querejeta R., González A. et al. Effects of loop diuretics on myocardial fibrosis and collagen type I turnover in chronic heart failure. J Am Coll Cardiol. 2004; 43(11): 2028-2035.

20. TORAFIC Investigators Group. Effects of prolonged-release torasemide versus furosemide on myocardial fibrosis in hypertensive patients with chronic heart failure: a randomized, blinded-end point, activecontrolled study. Clin Ther. 2011; 33(9): 1204-1213.

21. Mullens W., Damman K., Harjola V. et al. The use of diuretics in heart failure with congestion - a position statement from the Heart Failure Association of the European Society of Cardiology. Eur J Heart Fail. 2019; 21(2): 137-155.

\section{ORCID and contributionship:}

Maryana M. Rosul: 0000-0002-2106-5386 ${ }^{A, B, D, E}$

Miroslava M. Bletskan: 0000-0002-8069-6145 A,B,D

Natalia V. Ivanio: 0000-0003-0147-2176 ${ }^{\text {B,F }}$

Marina O. Korabelschykova: 0000-0002-7632-4322 ${ }^{B, F}$

\section{Conflict of interest:}

The Authors declare no conflict of interest.

\section{CORRESPONDING AUTHOR}

Maryana M. Rosul

Uzhhorod national university

148 Sobranetska Str., 88000 Uzhhorod, Ukraine

tel: +380506115733

e-mail:maryana.rosul@uzhnu.edu.ua

Received: 17.11 .2020

Accepted: 08.03.2021

A - Work concept and design, B - Data collection and analysis, C - Responsibility for statistical analysis,

$\mathbf{D}$-Writing the article, $\mathbf{E}$-Critical review, $\mathbf{F}$ - Final approval of the article 